\title{
A CONSTRUÇÃO DA IDENTIDADE DOCENTE DE LICENCIADOS EM FÍSICA E MATEMÁTICA: RELATOS SOBRE O PROCESSO FORMATIVO
}

\author{
THE CONSTRUCTION OF THE TEACHING IDENTITY OF LICENSES IN \\ PHYSICS AND MATHEMATICS: REPORTS ON THE FORMATION PROCESS
}

\author{
LA CONSTRUCCIÓN DE LA IDENTIDAD DOCENTE DE LAS LICENCIAS EN \\ FÍSICA Y MATEMÁTICAS: INFORMES SOBRE EL PROCESO DE FORMACIÓN
}

\author{
Álex de Carvalho Ferreira ${ }^{1}$ \\ Adriana Guerra ${ }^{2}$
}

\begin{abstract}
Resumo: Apresentamos nesse artigo um diálogo sobre o processo formativo nos cursos de licenciatura em Física e Matemática através de relatos de experiência, tendo como foco a formação de professores dessas áreas, bem como o processo da construção identitária no percurso da formação inicial. Embasado nos estudos sobre identidade docente (DUBAR, 2005; GOMES, 2008; PIMENTA; LIMA, 2004) e considerando a importância sobre como ocorre o processo de construção dessa identidade docente, discutimos sobre os caminhos e experiências que contribuíram para essa construção, a fim de propor uma discussão que possa contribuir, por meio da reflexão sobre ações pedagógicas e identidade docente, complementando estudos já existentes para uma melhor compreensão no processo de formação de professores, principalmente, o Ensino de Física e Matemática.
\end{abstract}

Palavras-chave: Formação de professores. Processo formativo. Identidade docente.

\begin{abstract}
In this article we present a dialogue about the formative process in undergraduate courses in Physics and Mathematics through experience reports, focusing on the training of teachers in these areas, as well as the process of identity construction in the course of initial formation. Based on studies on teaching identity (DUBAR, 2005; GOMES, 2008; PIMENTA; LIMA, 2004) and considering the importance of how the process of building this teaching identity occurs, we discuss the paths and experiences that contributed to this construction in order to propose a discussion that can contribute, by reflecting on pedagogical actions and teacher identity, complementing existing studies for a better understanding in the process of teacher training, especially the teaching of Physics and Mathematics.
\end{abstract}

Keywords: Teacher training. Formative process. Teaching identity.

Resumen: En este artículo presentamos un diálogo sobre el proceso formativo en las carreras de grado en Física y Matemáticas a través de relatos de experiencia, enfocándonos en la formación de docentes en estas áreas, así como el proceso de construcción de identidad en el curso de formación inicial. A

\footnotetext{
${ }^{1}$ Licenciado em Física pela Universidade Estadual do Sudoeste da Bahia (UESB). Mestre em Educação pela Universidade Estadual do Sudoeste da Bahia (UESB). Integrante do Centro de Pesquisa e Estudos Pedagógicos (CEPEP); e Membro do Grupo de Pesquisa Linguagem e Educação (GPLED).

${ }^{2}$ Licenciada em Matemática pela Universidade Estadual de Santa Cruz (UESC). Mestre em Educação Científica e Formação de Professores pela Universidade Estadual do Sudoeste da Bahia (UESB). Doutoranda em Educação pela Universidade Federal da Bahia. Integrante do Centro de Pesquisa e Estudos Pedagógicos (CEPEP).
}

Revista de Estudos em Educação e Diversidade. v. 1, n. 1, p. 83-96, jul./set. 2020.

Disponível em: http://periodicos2.uesb.br/index.php/reed

ISSN: 2675-6889 


\section{Revista de Estudos em Educação e Diversidade}

partir de estudios sobre identidad docente (DUBAR, 2005; GOMES, 2008; PIMENTA; LIMA, 2004) y considerando la importancia de cómo se da el proceso de construcción de esta identidad docente, se discuten los caminos y experiencias que contribuyeron a esta construcción con el fin de proponer una discusión que pueda contribuir, al reflexionar sobre las acciones pedagógicas y la identidad docente, complementando los estudios existentes para un mejor entendimiento en el proceso de formación docente, especialmente la enseñanza de la Física y la Matemática.

Palabras clave: Formación docente. Proceso formativo. Identidad docente.

\section{Introdução}

Pensar no processo formativo para a docência nos cursos de licenciatura da área de Conhecimento de Natureza, especificamente Física e Matemática, com suas similaridades e distanciamentos, foram o pontapé inicial para a escrita desse artigo. Assim, identificamos que a opção pela licenciatura nessas áreas, em geral, não representa (de início) a opção pela docência como profissão. Como esses cursos oferecem outras áreas de atuação, chegamos assim a seguinte problemática: como ocorre a construção da identidade docente, no percurso da formação inicial de professores licenciados em Ciências da Natureza e Matemática? Adotamos como dados de análise a nossa própria experiência formativa, por meio de relatos sobre como "construímos" essa identidade docente, refletindo, principalmente a trajetória da nossa formação inicial, mas considerando a nossa história pessoal, uma vez que não podemos separar a identidade profissional da pessoal.

Discutir a identidade docente nos leva a considerar, primeiramente, a origem da profissão docente e das licenciaturas em Física e Matemática no Ensino Superior; evidenciar os contextos e modelos de formação e os principais problemas desde a criação dos cursos até a atualidade; o distanciamento da pratica profissional docente (teoria sem prática) e a dualidade entre os conhecimentos profissionais (supervalorização dos específicos em detrimento dos pedagógicos). Esses problemas passam a influenciar na construção da identidade docente e, consequentemente, no desenvolvimento profissional e na qualidade da Educação.

Partindo dessas impressões e/ou constatações evidenciamos a importância da discussão dessa temática, tendo como dados principais os relatos de experiência em que buscaremos analisar como a construção dessa identidade tem acontecendo nos cursos de licenciatura em Física e Matemática, ao tempo em que também identificamos as lacunas, práticas e experiências formativas que precisam ser preenchidas/reformuladas/intensificadas, 


\section{Revista de Estudos em Educação e Diversidade}

REED

para que os processos formativos nessas licenciaturas formem um profissional docente de excelência.

\section{Formação de professores de Física e Matemática}

A universidade é um lugar onde os valores e as práticas educacionais podem ser vivenciadas e também um espaço para a construção/produção de conhecimentos. As perspectivas da educação atual remetem à necessidade de dinamização do processo de ensino e revisão da formação do professor, de modo que supere a condição de mero transmissor de conhecimento e proporcione a formação de sujeitos que sejam capazes de analisar a sua prática, intervir e construir um percurso inovador.

A criação dos primeiros cursos de Matemática e da área de Ciências da Natureza (Física, Química e Biologia) ocorreu na década de 1930. Nessa mesma época, o processo de industrialização e a administração pública estavam em alta, além da inexistência, no país, de mão de obra qualificada para este mercado de trabalho, o que ocasionou na carência e na exigência da formação de especialistas e pesquisadores em diversas áreas de atuação; profissionais desta área específica, Matemática, técnicos em finanças e pesquisadores sociais (SANTOS, 2002).

Entretanto, percebemos que mesmo passado tantos anos, ainda é evidente, desde os seus primórdios vários problemas relacionados ao processo formativo e isto pode estar integrado a prática de ensino. Conforme Diniz-Pereira (2014) existe alguns modelos de formação envolvidos na prática docente do ensino superior. Dentre eles a racionalidade técnica, com uma concepção instrumental sobre o levantamento de problemas; a racionalidade prática, que apresenta uma perspectiva mais interpretativa; e a racionalidade crítica, que vem com uma visão política explícita sobre o assunto (DINIZ-PEREIRA, 2014).

O modelo da racionalidade técnica é considerado ultrapassado, embora esteja presente, ainda, em muitas instituições de ensino superior. Segundo Diniz-Pereira, (1999) nesse modelo de formação, o professor é compreendido como um técnico, um especialista que aplica com rigor, na sua prática cotidiana, as regras que procedem do conhecimento específico e do conhecimento pedagógico. Acredita-se que a oferta de disciplinas específicas e pedagógicas passa a ser condição necessária para uma boa formação. Nessa perspectiva, vemos o quanto este modelo é criticado, quando referente a separação que existe entre a teoria e a prática no exercício docente, a atenção voltada a formação teórica (que deixa de lado a formação prática) 


\section{Revista de Estudos em Educação e Diversidade}

REED

e por fim, a idealização de que para ser um bom professor é necessário o conhecimento específico e o domínio da área de atuação.

O segundo modelo alternativo de formação de professores é a racionalidade prática, que segundo Diniz-Pereira (2014) vem ocupando mais espaço na Educação. Neste modelo o professor é considerado um profissional autônomo; aquele que reflete, toma decisões, é criativo durante a sua ação pedagógica, a qual é compreendida como um fenômeno complexo, singular, instável e carregado de incertezas e conflitos de valores. Neste modelo, a prática não é somente um momento de aplicar o conhecimento científico e/ou pedagógico, mas também de produção, reflexão. Esse é o espaço em que novos conhecimentos são, constantemente, provocados e transformados (DINIZ-PEREIRA, 2014).

Por fim, a racionalidade crítica, modelo em que o professor é considerado como uma pessoa que instiga questionamentos, embora, nos modelos técnico e prático o professor também exerça essa função. No entanto, esses modelos não associam a mesma visão quanto à concepção a respeito da natureza do trabalho docente (DINIZ-PEREIRA, 1999). No modelo crítico "o professor é frequentemente definido como alguém que levanta problemas e dirige um diálogo crítico em sala de aula" (SCHON, 1992 apud DINIZ-PEREIRA, 1999, p. 40).

O nosso desafio continua sendo o de romper com propostas conservadoras e simplistas de formação docente baseadas no modelo da racionalidade técnica e continuar sonhando com a possibilidade de iniciativas que se inspirem nos modelos da racionalidade crítica visando a transformação da sociedade e a luta incessante dos educadores por justiça social (DINIZ-PEREIRA, 2014, p.41).

Para o processo formativo nos cursos de licenciatura corresponder às necessidades, orientar e possibilitar ao licenciando uma boa prática de ensino na sua atuação futura como professor é necessária uma formação voltada para a racionalidade crítica. Nesta o formando terá a liberdade de questionar, criar, desenvolver, se envolver, ser inovador, participante, mediador, ativo, de modo que existam possibilidades para assumir um papel importante em todo o processo formativo.

Os cursos de nível superior, mais especificamente das Ciências da Natureza e da Matemática precisam, não apenas de conteúdo específicos, de uma prática de resolução de exercícios, mas de relacionar a realidade da prática com a teoria no contexto vivido e assim, desperte a curiosidade e interesse pela formação pretendida. 


\section{Revista de Estudos em Educação e Diversidade}

REED

\section{A identidade docente no processo formativo}

As bases teóricas sobre identidade docente que constitui esse trabalho repousam nas ideias e estudos de Claude Dubar (2005), o qual define a socialização como um processo de ser e estar no mundo, em que o indivíduo se relaciona consigo mesmo, com as outras pessoas e com o seu meio, desempenhando o papel social. Para Dubar (2005) a socialização "se torna um processo de construção, desconstrução e reconstrução de identidades ligadas às diversas esferas de atividade" (p. 17). Nessa perspectiva, o autor compreende que a identidade se constrói nas relações, ou seja, ela resulta de um processo de socialização. "A identidade nada mais é que o resultado a um só tempo estável e provisório, individual e coletivo, subjetivo e objetivo, biográfico e estrutural, dos diversos processos de socialização que, conjuntamente, constroem os indivíduos e definem as instituições" (DUBAR, 2005, p.136).

Ainda, de acordo com o autor, a construção das identidades sociais envolve a dimensão individual (carrega marcas de nossas histórias de vida), dimensão coletiva, (que carrega marcas de um grupo da qual fazemos parte) e da cultura da profissão. A construção dessa identidade também carrega em si marcas e elementos, dos quais a profissão é constituída. Assim, segundo Gomes (2008, p. 5), "pressupondo-se que toda profissão afirma uma identidade, logo existe uma identidade profissional do professor, ou seja, uma maneira de ser professor". Assim, toda identidade profissional é do mesmo modo social, não sendo distinta da identidade docente, onde essas identidades sociais definem o sentimento de pertença do grupo.

Pimenta e Lima (2004) apontam sobre a identidade profissional, afirmando que os cursos de formação de professores possibilitam entrar em contato com elementos indispensáveis para a construção da identidade profissional docente. Para elas, "a identidade do professor é construída ao longo de sua trajetória como profissional do magistério. [...] Sendo o estágio a iniciação à docência, por excelência, um lugar de reflexão sobre a construção e o fortalecimento da identidade" (p.62). Desse modo, para as autoras a identidade é construída ao longo da vida e a identidade profissional ao longo da trajetória profissional.

Nesta perspectiva, os autores, Garcia, Hypólito e Vieira (2005), apontam que a identidade profissional dos docentes é compreendida como uma construção social marcada por vários fatores que interagem entre si, resultando numa série de representações que os docentes fazem de si mesmos e de suas funções, demonstrando consciente ou inconscientemente, relações das quais certamente fazem parte de suas histórias de vida, suas Revista de Estudos em Educação e Diversidade. v. 1, n. 1, p. 83-96, jul./set. 2020. 


\section{Revista de Estudos em Educação e Diversidade}

REED

condições concretas de trabalho ou, eventualmente, imaginário recorrente acerca dessa profissão.

Por isso, as experiências vividas dentro e fora da universidade, contribuem para a construção da identidade docente, pois ela agrega a história individual e coletiva dos sujeitos que revelam experiências sociais. No entanto, é na formação inicial, por meio das disciplinas do estágio e da iniciação à docência, que o estudante tem acesso a vários conhecimentos e saberes que podem possibilitar o seu ingresso na carreira docente. Portanto, os cursos de licenciatura (formação inicial) habilitam os estudantes universitários a tornarem-se professores (MELLO, 1998).

Desse modo, a construção da identidade profissional realiza-se na fase de formação inicial (NASCIMENTO, 2002) e a sua caracterização dar-se por meio da dimensão individual e coletiva do sujeito, por isso o processo biográfico torna-se muito importante. Assim sendo, a identidade docente se constitui num processo de formação, na qual envolve a formação inicial e contínua num duplo processo: a formação institucional, que se dá através dos cursos de formação; e a autoformação, construída ao longo da vida, através da reconstrução das experiências profissionais, dos saberes e da prática pedagógica. Consideramos, portanto que é através dessa identidade que nós percebemos, nos vemos e desejamos que nos vejam.

\section{A construção da identidade docente dos licenciados em Física e Matemática: Relatos de experiência}

Nesse tópico apresentamos relatos, pessoais, sobre a construção da identidade docente, enfatizando a experiência formativa, onde consideramos como a mais importante durante o processo da formação inicial. O primeiro relato sinaliza a importância do Estágio Supervisionado para um Licenciado em Física e o segundo a descoberta na prática docente de uma licenciada em Matemática

\section{Relato 1}

Nesse relato apresento a minha experiência em sala de aula como estagiário na disciplina Estágio Supervisionado II, III e V como graduando do curso de Licenciatura em Física na Universidade Estadual do Sudoeste da Bahia/UESB. Essa experiência deu-se em uma escola pública da rede estadual de ensino, localizada no centro da cidade de ItapetingaBahia. Assim, proponho dialogar com a construção da identidade docente no percurso do Revista de Estudos em Educação e Diversidade. v. 1, n. 1, p. 83-96, jul./set. 2020. 


\section{Revista de Estudos em Educação e Diversidade}

REED

estágio supervisionado, descrevendo os momentos de observação, coparticipação e regência e; narrar aspectos de reflexões sobre o ser professor (como futuro professor), visando expor aprendizagens e vivências que me possibilitaram a mudança em relação à docência.

O primeiro momento vivenciado durante o estágio foi o da observação. Momento nostálgico e reflexivo, que remetia a lembranças da época em que era aluno do Ensino Médio. O período da observação permitiu trazer à tona vivências da sala de aula, que provocaram uma reflexão sobre os métodos utilizados pelos professores na sua prática de ensino. Estar de volta à sala de aula sob um novo olhar, uma nova perspectiva, de aprender observando, ficar atento a tudo que está sendo feito sem poder interferir, é se imaginar como professor e desejar fazer igual ou diferente dele.

São várias percepções construídas no período de observação e através delas, começamos a entender o trabalho do professor e a identificar os benefícios e as dificuldades enfrentadas por este. Observar as três turmas do Ensino Médio, permitiu entender que os métodos e a maneira de lidar são diversos; não somente pela diferença de conteúdo e idade dos alunos, mas pelo comportamento, diferentes métodos que o mesmo professor desenvolveu em sua prática de ensino com cada turma.

Recordo que nas aulas do segundo ano ocorriam maiores explicações, dinâmicas que possibilitava maior aprendizagem e participação dos alunos nas, demonstravam entender os conteúdos com mais facilidade. Assim, essa experiência me fez entender que a maneira como o professor ministra as suas aulas pode favorecer ou não a melhor compreensão do aluno. Com isso, é importante que o professor reflita sobre a sua forma de ensinar, a fim de promover mudanças no processo de aprendizagem dos alunos.

Com a ampliação da compreensão sobre o funcionamento da escola e das aulas, a etapa seguinte é a coparticipação, momento que permite interferir (poucas vezes) durante as aulas e inicia a prática de ensino nas três turmas do Ensino Médio no período de um mês. Esta experiência é um pouco diferente, visto que em alguns momentos da aula houvera a oportunidade de apresentar exemplos relacionados aos conteúdos ministrados pelo professor e auxiliar na explicação de algumas questões abordadas que não estavam sendo compreendidas pelos alunos. Essa sensação, mesmo sendo rápida, me fez querer assumir a aula por completo, não porque estivesse sendo monótona ou ministrada de forma incorreta e sim, por despertar em mim o desejo de lecionar. Com isso, percebi que estava gostando da ideia de "ser professor". 


\section{Revista de Estudos em Educação e Diversidade}

REED

Recordo-me que em certo momento da aula, o professor passou uma atividade e pude ajudar os alunos a entender o conteúdo e a cada explicação que eu dava, mais confiante me sentia para ensinar. Como as aulas seguiam um padrão tradicional (lousa, pincel e livro) maior era a vontade de usar outras metodologias. Utilizar experimentos simples em sala de aula foi uma das minhas sugestões ao professor, mas este apresentou recusa mediante argumento de não ter tempo suficiente para isso. Estando envolvido na ajuda aos alunos, o tempo da aula acabou, mas o desejo de ensinar continuou. Ansioso pela próxima aula, fui percebendo que o tempo da aula era pouco para a quantidade de conteúdos a serem trabalhados e isso é uma das dificuldades dos professores de Física. Planejar duas aulas por semana e dar conta da ementa, exige um planejamento, mas a vontade de usar novas metodologias ainda persistia.

O período da regência foi um dos mais esperados no curso, pois a cada estágio que cursava me sentia mais preparado para dar aula. Assim como os outros, a regência seria nas três turmas do Ensino Médio, só que dessa vez, no período de dois meses. Ao iniciar o planejamento das aulas para regência dei conta de que tudo tem que ser planejado; que dar aula não é tão simples assim. É necessário um mapeamento organizado do que se pretende ensinar, quais instrumentos serão usados, quantidade de questões, tempo para resolução e explicação, etc. Isso tudo foi novo para mim, embora, já soubesse elaborar um plano de aula. No entanto, porém não tinha noção do quão importante ele é na prática.

Colocar em ação o plano elaborado, nem sempre é fácil, percebi nas aulas que todo professor precisa ter um "plano B", pois não pode estar preso somente a um método para ensinar. É preciso estar ciente de que existem outras formas para isso e que devemos exercer. Dar aula, também me fez perceber que é preciso ter paciência, principalmente com os alunos desinteressados e com dificuldades em entender Física. É preciso explicar e reexplicar de formas diferentes e, por diversas vezes até, o mesmo assunto.

Desse modo, numa licenciatura em Física, as metodologias não devem apenas estar focadas em seus conteúdos específicos, mas especialmente na investigação e experimentação, no aprender praticando, aproximando o cotidiano da Ciência, promovendo contribuições para aprendizagem do aluno (; CARVALHO; GIL-PÉREZ, 1993; GONÇALVES, 2000).

Assim, a experiência do Estágio Supervisionado foi rica e prazerosa. As aprendizagens sobre a docência e ser professor de fato ocorreram. Essa experiência na qual tive a oportunidade de vivenciar se configurou como algo imprescindível para a minha formação docente, pois por meio deste pude fazer a relação entre teoria e prática e concluir que o ato de educar vai além de uma carga horária teórica. Que o ensino precisa ser conduzido de forma Revista de Estudos em Educação e Diversidade. v. 1, n. 1, p. 83-96, jul./set. 2020. 


\section{Revista de Estudos em Educação e Diversidade}

REED

interativa, planejada, dinâmica, com olhar curioso e, novas expressões do conteúdo de modo a proporcionar incentivos e prazer aos alunos.

João Pedro, licenciado em Física no ano de 2016.

\section{Relato 2}

Escrever ou falar sobre a minha formação docente, talvez, seja o de uma história um pouco confusa, pois iniciei os estudos no Ensino Superior em 2007 imaginando, nunca ser professora. Comecei pelo bacharelado em Matemática na Universidade Estadual de Santa Cruz (UESC), com várias expectativas sobre caminhos que poderia seguir, mas dentre esses, jamais, estava o do exercício docente.

No segundo semestre, houve a oportunidade de ser bolsista de um projeto de extensão (Caminhão Com Ciência) que era integrado as áreas de Matemática, Física, Química e Ciências Biológicas. As atividades desenvolvidas pelos participantes (bolsistas) eram voltadas para o ensino das suas áreas específicas de formação. A agenda desse projeto sempre foi cheia e, assim, todo final de semana estava na estrada para apresentar os trabalhos desenvolvidos para atender a diversas comunidades. A área da Matemática, especificamente, apresentava jogos didáticos que despertavam a curiosidade e o interesse do aluno pela aprendizagem da Matemática, os quais poderiam ser trabalhados pelo professor em sua prática pedagógica.

Essa experiência foi muito boa para o meu crescimento acadêmico. Durante esse período houve duas professoras muito importantes, que sempre sinalizam: "Ana Maria, você tem muita afinidade com a área de ensino. Você tem certeza que está no curso certo?”. E com essas afirmações e interrogações comecei a refletir sobre o meu processo formativo.

No início do ano de 2009, mesmo cursando o bacharelado em Matemática, tive a oportunidade de ser professora de Matemática e Física do Ensino Fundamental e Médio em uma escola pública da cidade de Itabuna-BA onde atuei até 2011. Foi a partir desta experiência que comecei a me ver como professora. Percebi que u gostava de ensinar e que eu tinha, sim, afinidade com a área de Educação.

Dessa forma, encantada com o ensino da Matemática, desisti em 2010 do curso bacharelado e decidi prestar vestibular para a licenciatura em Matemática. Em 2011 iniciei este curso com novas expectativas, diferentes daquelas criadas em 2007. Nessa perspectiva, convalidei tudo que tinha cursado no bacharelado e conclui a licenciatura em três semestres. Neste período estudei as disciplinas pedagógicas ofertadas no curso, o que possibilitou a 


\section{Revista de Estudos em Educação e Diversidade}

minha certeza neste processo formativo. Vale ressaltar, que todo encanto das disciplinas pedagógicas era pelas leituras desenvolvidas, pelas discussões abordadas nos textos. No entanto, não era apresentada pelos professores responsáveis pela disciplina nenhuma relação com a prática de ensino, em sala de aula, pois tudo neste momento de estudo era apenas teoria.

E assim, desde 2009 não parei de lecionar. Passei por diversas experiências, notadamente, no ensino da Matemática como no Ensino Fundamental e Médio, em cursos técnicos, na Educação de Jovens e Adultos e no Ensino Superior (tutoria). E a partir dessas vivências, considero a minha descoberta como professora o que proporcionou a minha formação e a construção da minha identidade docente. Em outras palavras, foram os saberes adquiridos com as experiências, vivências, trocas com outros profissionais da área, estudos, reflexões, preocupações nessa caminhada que promoveram a construção e reconstrução da minha identidade de professora. Contribuíram e continua contribuindo para o desenvolvimento de uma boa prática de ensino.

Ana Maria, licenciada em Matemática no ano de 2012.

\section{Discutindo os relatos}

Os relatos apresentam histórias, vivências, aspirações, formações, construções distintas que alimentaram a construção de uma mesma formação: a profissão de professor. Todas essas transições contribuíram de alguma forma para a construção da identidade docente por meio da socialização com o outro. Hoje, ambos, com o mesmo entusiasmo de continuar na docência, apesar das dificuldades, das resistências encontradas no caminho, ainda percorrem o caminho da docência.

O primeiro relato apresenta o formando em suas tarefas de Estágio Supervisionado através de mobilizações como: o desejo de participar, juntamente, com o professor em sua prática de ensino ou mesmo de substituí-lo; dar opiniões do como pode ou poderia fazer; desenvolver diferentes metodologias de ensino com os alunos; notar que independentemente dos alunos apresentarem a mesma faixa etária ou do professor trabalhar em várias turmas, exigem-se métodos de ensino diversos para que possibilite a aprendizagem; a indispensabilidade do professor refletir sobre a sua própria prática em sala de aula; o gostar daquele espaço - certifica desta maneira a sua descoberta como professor. 


\section{Revista de Estudos em Educação e Diversidade}

REED

Sair daquele espaço, mas querendo ficar mais; perceber o horário das aulas ficarem ou ser curto para tantos conteúdos a serem aplicados, de acordo a ementa; constatar a necessidade de uma carga horária maior para a disciplina de Física. Tudo isso é gerado, a partir de reflexões, vivências e inquietações que provocadas através de certa mudança, o que nesse momento pode se chamar de construção da identidade docente.

Ao correlacionar o primeiro relato (professor de Física) com o segundo (professora de Matemática), é notório que as experiências foram distintas e não muito agradável para a professora de Matemática, visto a mesma não viver momentos cruciais que o Estágio Supervisionado tem por objetivo proporcionar sobre as experiências e vivências da prática docente.

Nessa perspectiva, podemos perceber certa diferença entre ambos, pois um já queria ser professor e outro descobriu depois, com o desenvolvimento de atividades relacionadas ao ensino no período que cursava um bacharelado, tendo nessas vivências, experiências o impulso que a fez refletir sobre a sua carreira profissional.

Enquanto, a construção identitária docente do professor de Física se deu a partir dos Estágios Supervisionados, a professora de Matemática tomou um rumo distinto, onde a mesma teve acesso diretamente na sala de aula como docente e não como estagiária: com erros e acertos; refletindo sobre o que poderia melhorar; as práticas de sala de aula, como os alunos poderiam aprender; vivências com outros professores; estudos. Tudo isso fez parte da construção da sua identidade docente. Não diferente do primeiro, entretanto assumindo papéis distintos.

Vale ressaltar que foi a partir das experiências vivenciadas que ambos perceberam a relação da teoria e prática. Todo estudo através das disciplinas pedagógicas foi associado e notado através dos métodos utilizados pelo professor da disciplina de Física durante o Estágio Supervisionado, e em todos os momentos das práticas de ensino como professora de Matemática, o que tornou mais interessante e curiosa a experiência de viver e ser professor.

Contudo, apesar das vivências e experiências serem divergentes, eventualmente, a construção identitária docente se estabeleceu: com o mesmo processo de socialização e reflexão; de perceber a necessidade de melhorias na prática docente; do gostar de ensinar; de constatar as suas vantagens e desvantagens como um profissional da área da Educação; de perceber a necessidade de estudar cada vez mais, a fim de atender as diversas necessidades de aprendizagem do seu aluno; das inquietações; das dúvidas; enfim das diversas interrogações, exclamações e afirmações que ocorrem frequentemente nessa caminhada diária do professor. 


\section{Considerações Finais}

A construção da identidade docente é um processo que está sempre em mudanças constantes, devido as socializações, as interações com o meio e pelas reflexões serem diversas. Esta se inicia a partir do contato com a sala de aula, seja como estagiário ou como professor de tal disciplina, pois este é o espaço de consolidação da descoberta do ser professor e estabelecer certa concepção de identidade.

Através dos relatos é clara a necessidade da coletividade; ninguém se constrói sozinho, pois existe a dependência do outro ou da participação com o meio. Para constituir certa identificação com o fazer, existe o processo do reconhecimento com base na observação, na participação, nos planejamentos, na reflexão, nas inquietações, nas dúvidas, entre outras diversas questões. No entanto, tudo isso fortalece continuamente a construção da identidade docente.

A formação inicial, eventualmente, começa em um curso de graduação, dentro de uma sala de aula, como aluno, mas a construção da identidade docente está relacionada, também, ao envolvimento da teoria (todos aqueles textos, aquelas abordagens teóricas discutidas no curso) e a prática (as ações do professor, os métodos, as técnicas utilizadas a fim de favorecer a aprendizagem do aluno).

Possivelmente, os cursos de licenciatura, especificamente, das áreas de Matemática e Ciências da Natureza poderiam focar, com certa paridade, nas abordagens pedagógicas assim como foca significativamente nos conteúdos específicos; compreender a necessidade de priorizar, no processo formativo, a relação das teorias com a prática, pois discutir teorias sem demonstrar como elas estão envolvidas no exercício docente não desperta curiosidade ao formando, principalmente, quando o mesmo não conhece, como professor, a realidade da sala de aula.

O Estágio Supervisionado é a única atividade acadêmica considerada como o momento de associar teoria e prática. No entanto existem, ainda, muitas falhas em seu desenvolvimento, talvez, não pelos formandos, mas pelos professores dos cursos de licenciatura em acompanhar os alunos nessa tarefa, a qual deve ser supervisionada, questionada, ou seja, observada com o objetivo de contribuir para a formação do estagiário.

Todavia, o Estágio Supervisionado pode ser o momento crucial; um processo de descoberta, de identificação para aqueles formandos que, possivelmente, não tiveram a Revista de Estudos em Educação e Diversidade. v. 1, n. 1, p. 83-96, jul./set. 2020. 


\section{Revista de Estudos em Educação e Diversidade}

oportunidade de conhecer a sala de aula assumindo o papel de professor. A construção da identidade docente na formação inicial de qualquer formando, consideravelmente, ocorre a partir de uma manifestação de sentimentos: o medo do novo ou dos seus objetivos não serem alcançados; a alegria de perceber a aprendizagem dos seus alunos; a tristeza, pelos desprivilegios e pela desvalorização da função professor; o amor pela docência; a ansiedade, surgida durante o percurso do tornar-se professor; dentre outros que surgem durante toda a carreira profissional docente.

\section{Referências}

CARVAlHO, Anna Maria Pessoa de.; GIL-PÉREZ, Daniel. Formação de Professores de Ciências. SP: Cortez, 1993.

DINIZ-PEREIRA, Júlio Emílio. As licenciaturas e as novas políticas educacionais para a formação docente. Educação \& Sociedade, ano XX, nº 68, Dez. 1999.

Da racionalidade técnica à racionalidade crítica: formação docente e

transformação social. Perspectiva em Diálogo - Revista de Educação e Sociedade, Naviraí, v.01, n.01, p. 34-42, jan-jun.2014.

DUBAR, Claude. A socialização: construção das identidades sociais e profissionais. Tradução de Andréia Stahel M. da Silva. São Paulo: Martins Fontes, 2005.

GARCIA, Maria Manuela Alves; HYPOLITO, Álvaro Moreira; VIEIRA, Jarbas Santos. As identidades docentes como fabricação da docência. Educação e Pesquisa, São Paulo, v. 31, n. 01, p. 45-56, 2005.

GOMES, Alberto Albuquerque. A construção da identidade profissional do professor: uma análise de egressos do curso de Pedagogia. VI Congresso Português de Sociologia - mundos sociais: saberes e práticas. Universidade Nova de Lisboa. Faculdade de Ciências Sociais e Humanas. 2008. p.1-15.

GONÇALVES, Terezinha Valim Oliver. Ensino de Ciências e Matemática e formação de professores: marcas da diferença. Tese (Doutorado) Programa de Pós-Graduação em Educação. Universidade Estadual de Campinas. Campinas: SP, 2000.

MELLO, Roseli Rodrigues. Os saberes docentes e a formação cotidiana nas séries iniciais do Ensino Fundamental (um estudo de casos múltiplos de tipo etnográfico). Tese (Doutorado em Educação). Universidade Federal de São Carlos. 1998.

NASCIMENTO, Maria Augusta. A construção da identidade profissional na formação inicial de professores. Dissertação de Doutoramento. Coimbra: Faculdade de Psicologia e de Ciências da Educação, 2002.

Revista de Estudos em Educação e Diversidade. v. 1, n. 1, p. 83-96, jul./set. 2020. 


\section{Revista de Estudos em Educação e Diversidade}

PIMENTA, Selma Garrido.; LIMA, Maria Socorro Lucena. Estágio e Docência. 2. ed. São Paulo: Cortez, 2004.

SANTOS, Cassio Miranda dos. Os primeiros passos da Pós-Graduação no Brasil: a questão da dependência. Ensaio: Avaliação e Políticas Públicas em Educação, Rio de Janeiro, v.10, n.37, p.479-492, out./dez. 2002.

Recebido em: 16 de agosto de 2020.

Aprovado em: 20 de setembro de 2020. 